\title{
Autosomal dominant polycystic kidney disease (ADPKD, MIM 173900, PKD1 and PKD2 genes, protein products known as polycystin-1 and polycystin-2)
}

\author{
Catherine Boucher ${ }^{1}$ and Richard Sandford ${ }^{*, 1}$ \\ ${ }^{1}$ Department of Medical Genetics, Cambridge Institute for Medical Research, Addenbrooke's Hospital, Hills Road, \\ Cambridge CB2 $2 X Y$, UK
}

Autosomal dominant polycystic kidney disease (ADPKD) is a common inherited nephropathy affecting over 1:1000 of the worldwide population. It is a systemic condition with frequent hepatic and cardiovascular manifestations in addition to the progressive development of renal cysts that eventually result in loss of renal function in the majority of affected individuals. The diagnosis of ADPKD is typically made using renal imaging despite the identification of mutations in PKD1 and PKD2 that account for virtually all cases.

Mutations in PKD1 are associated with more severe clinical disease and earlier onset of renal failure. Most PKD gene mutations are loss of function and a 'two-hit' mechanism has been demonstrated underlying focal cyst formation. The protein products of the PKD genes, the polycystins, form a calcium-permeable ion channel complex that regulates the cell cycle and the function of the renal primary cilium. Abnormal cilial function is now thought to be the primary defect in several types of PKD including autosomal recessive polycystic kidney disease and represents a novel and exciting mechanism underlying a range of human diseases.

European Journal of Human Genetics (2004) 12, 347-354. doi:10.1038/sj.ejhg.5201162

Published online 11 February 2004

Keywords: autosomal dominant polycystic kidney disease; ADPKD; diagnosis; PKD1; PKD2; polycystin; cilia

\section{Clinical features \\ Autosomal dominant polycystic kidney disease (ADPKD) is a common inherited nephropathy characterised by the age-related development of bilateral, multiple renal cysts leading to nephromegaly and renal failure (Figure 1). It is typically a late onset disorder with renal failure developing in the sixth-eighth decades of life. Considerable clinical variability in the age of onset of renal failure is observed within and between families. In addition to renal cysts, cysts occur in the liver (70\%) and pancreas $(5-10 \%) .{ }^{1}$ Cysts}

${ }^{*}$ Correspondence: Dr R Sandford, Department of Medical Genetics, Cambridge Institute for Medical Research, Addenbrooke's Hospital, Hills Road, Cambridge CB2 2XY, UK. Tel: + 441223 762616;

Fax: + 441223 331206;

E-mail: rns13@cam.ac.uk, www.cimr.cam.ac.uk/medgen/pkd/

Received 11 September 2003; revised 9 December 2003; accepted 11 December 2003 have also been reported in other organs such as the spleen, thyroid, arachnoid, seminal vesicles and prostate. ${ }^{2}$ The prevalence of all cystic manifestations increases with age. The number and size of hepatic cysts is also correlated with female gender, parity and severity of the renal disease. ${ }^{3}$ Massive polycystic liver disease, although rare, occurs predominantly in female subjects.

The main complications associated with renal cysts include renal failure, cyst infection and haemorrhage, renal stones and pain. Hepatic cysts may also be complicated by infection and haemorrhage.

Clinical predictors of more severe renal disease and progression to renal failure include male gender, early age of diagnosis, early age of diagnosis of hypertension, hepatic cysts in women, high parity, urinary tract infection, macroscopic haematuria and renal size expressed as renal volume. $^{4,5}$ 
Polycystic kidney disease C Boucher and R Sandford
Noncystic manifestations of ADPKD are also common. These include hypertension (70-80\%), cardiac valve anomalies $(25 \%)$ and intracranial vascular abnormalities including vascular aneurysms (8\%). Rupture of cerebral aneurysms is a recognised complication of ADPKD resulting in substantial morbidity and mortality and occurs at a rate of $\sim 1 / 2000$ person years, five times higher than in the general population. ${ }^{6,7}$ Abdominal wall hernias have also been associated with ADPKD. ${ }^{8}$ While diverticulosis of the colon is unlikely to be associated with ADPKD, reports suggest that diverticulitis may be more severe in ADPKD patients requiring more frequent surgical intervention. ${ }^{9,10}$

All the main extrarenal manifestations of ADPKD reported in adults have been reported in children. Their presence correlates with the severity of the renal disease. ${ }^{11,12}$ ADPKD may rarely present in utero or in the early postnatal period usually following the detection of renal cysts by detailed antenatal ultrasound scanning. In a large series of 83 cases identified from the literature, presenting in utero or in the early postnatal period, $43 \%$ of such cases died before 1 year of pulmonary or renal insufficiency with a substantial proportion (67\%) developing hypertension at a mean age of 3 years. ${ }^{13}$ Several cases of childhood onset end-stage renal failure (ESRF) were also identified in this group.

\section{Diagnosis and screening}

ADPKD is typically diagnosed in adults by the detection of bilaterally enlarged polycystic kidneys using trans-abdominal ultrasound scanning. This is a simple, widely available, noninvasive technique suitable for all ages. However, ADPKD in children, if detectable, may be unilateral or markedly asymmetrical leading to diagnostic difficulty and necessitating a different approach than in adults. ${ }^{14}$ Computed tomography (CT) and magnetic resonance imaging (MRI) are also used where additional information on renal structure and function are required or where ultrasound resolution is poor such as in the obese individual. In addition to screening asymptomatic adult family members at-risk of inheriting ADPKD, individuals with renal tract symptoms or signs (children and adults) including macroscopic haematuria, loin pain, urinary infection or renal colic; early-onset hypertension; a sibling with early onset disease or a personal or family history of cerebral aneurysm, should also be offered screening.

For individuals at 50\% risk of inheriting ADPKD (firstdegree relatives of an affected individual) the diagnostic criteria of Ravine et $a l^{15}$ for PKD1-linked families are commonly used. The presence of at least two renal cysts (unilateral or bilateral) in individuals younger than 30 years may be regarded as sufficient to establish a diagnosis; among those aged 30-59 years, the presence of at least two cysts in each kidney and among those aged 60 years and

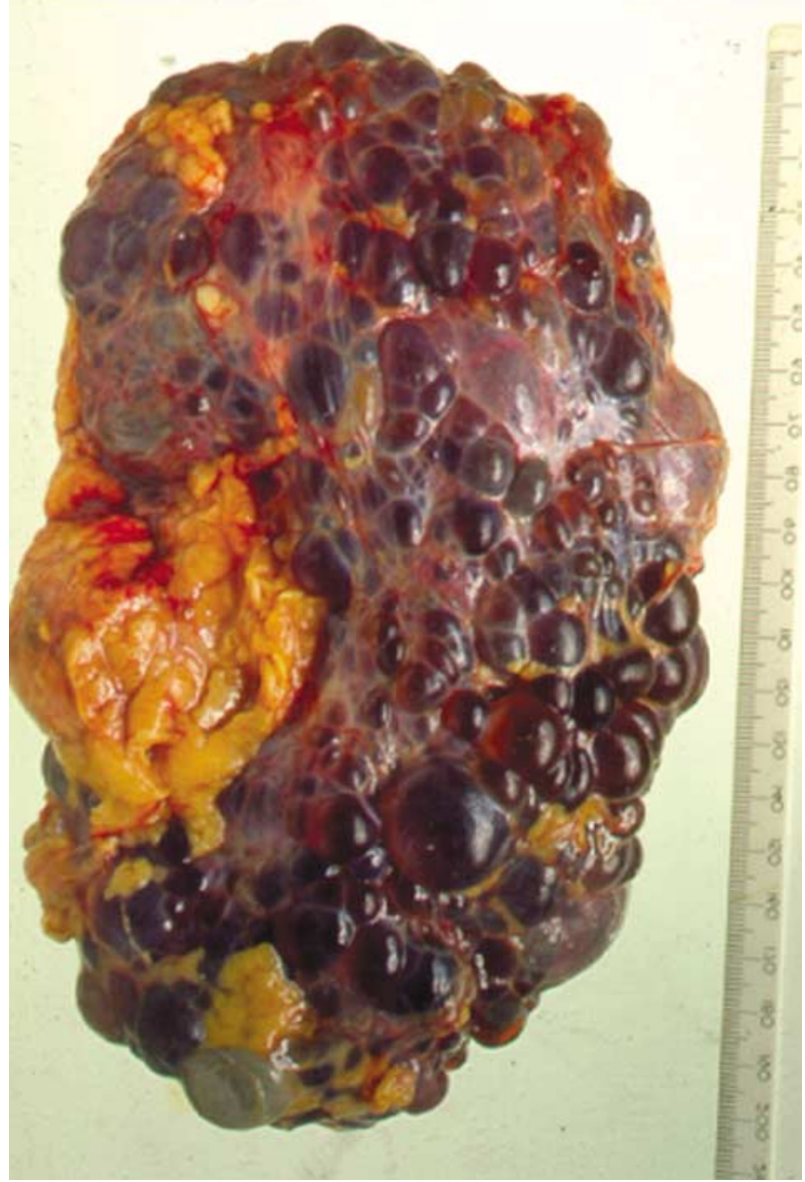

Figure 1 An explanted polycystic kidney demonstrating the massive enlargement due to multiple cysts.

above, at least four cysts in each kidney should be required. A significant false-negative rate occurs in children estimated at $36 \%$ in children under 10 years. ${ }^{16,17}$ However, over the age of 30 years, ADPKD is virtually excluded by a normal scan in PKD1 and PKD2 families. ${ }^{17-19}$

Predictive or prenatal diagnosis may also be offered to ADPKD families. Predictive testing may be offered to young adults with a normal renal ultrasound who wish to clarify their disease status without waiting for further scans up to the age of 30 years. It may also be appropriate for family members wishing to act as living related kidney donors. Prenatal diagnosis is only rarely performed for this typically late-onset disease, usually in cases of the earlyonset, in utero form, where there is considerable early morbidity and mortality and a high recurrence risk of $25 \%$ for all siblings of an affected child. ${ }^{13,20,21}$ This high recurrence risk is not observed in more distant relatives carrying the same PKD gene mutation, suggesting the coinheritance of a modifying gene. Genetic testing is usually carried out by linkage analysis as routine clinical mutation detection services have not been established in 
the majority of genetic centres worldwide, and may therefore be limited by the availability of other affected and unaffected family members. However, commercial PKD gene mutation screening (http://www.renaldx.com) has recently become available but high cost, uncertainty about mutation detection rates and the pathogenicity of missense mutations, especially in PKD1, may limit its clinical utility. Genetic counselling should be offered to all individuals and families with ADPKD. This will permit an informed choice to be made about diagnostic and screening tests. As ADPKD is usually a late-onset disorder, diagnosis as a young adult can have important implications. For example, a diagnosis of ADPKD can have important implications on choice of employment and provision of life, health and critical illness insurance. ${ }^{22}$

\section{Differential diagnosis}

Multiple renal cysts are present in a range of heritable, developmental and acquired disorders of which ADPKD is the commonest genetic cause. Acquired PKD can occur in chronic renal failure of any cause and is common in the dialysis population. ${ }^{23,24}$ Renal size is usually reduced in contrast to ADPKD. Other polycystic kidney diseases include multicystic dysplastic kidney, autosomal recessive polycystic kidney disease, tuberous sclerosis, von HippelLindau disease, nephronophthisis type 2, oro-facial digital syndrome type I and disease due to mutations in the HNF1 $\beta$ gene. Clinical and radiological features of these conditions should be sought and excluded in all cases of suspected ADPKD. Renal imaging should determine whether cysts are unilateral or bilateral, the cyst distribution within the kidneys, the presence of haemorrhagic and calcified renal cysts, renal size, solid renal masses, renal sinus cysts, and cysts in adjacent organs.

\section{Disease frequency}

ADPKD has been reported in all ethnic groups worldwide. It has a prevalence of approximately 1/1000 (1:400-1:1200) and is therefore one of the commonest monogenic disorders of man. ${ }^{25,26}$ Any ethnic variation in prevalence and disease severity has not been clearly defined. ${ }^{27}$

\section{Genetic heterogeneity}

Mutations in PKD1 (16p13.3) and PKD2 (4q21-q23) account for virtually all cases of ADPKD with approximately $85 \%$ in $P K D 1$. A third rare locus, $P K D 3$, remains to be identified. ${ }^{28}$

\section{Genes}

PKD1 has 46 exons spanning $52 \mathrm{~kb}$ of genomic sequence and a transcript size of $14 \mathrm{~kb}$, while the $5 \mathrm{~kb} P K D 2$ transcript consists of 15 exons and covers $68 \mathrm{~kb}$ of genomic DNA. ${ }^{29-31}$ Both PKD1 and PKD2 are ubiquitously expressed and are part of the polycystin gene family, which also includes PKDREJ, PKD1L1, PKD1L2, PKD1L3, PKD2L and $P K D 2 L 2 . .^{32-36}$ In addition, six $P K D 1$ pseudogenes with $\sim 95 \%$ homology to $P K D 1$ lie more proximal on chromosome $16 .^{37}$ As a consequence, only $3.5 \mathrm{~kb}$ of the PKD1 transcript is single copy, which has made mutation detection difficult. Mutations in PKD2 cause a milder phenotype with an average age of ESRF of 69 years compared to 53 years for PKD1 mutations. ${ }^{38}$

\section{Mutations}

A complete mutational analysis of the PKD1 and PKD2 genes with a detection rate of approximately $76 \%$ has now been achieved using conventional and long-range PCR. ${ }^{39,40}$ The majority of mutations are nonsense or frameshifting and predict a truncated protein product (see Table 1 for details of mutations identified). ${ }^{41,42}$ Although large deletions of PKD1 are described the frequency of this type of mutation is not known. A contiguous gene syndrome involving deletions of PKD1 and TSC2 has also been described where patients develop severe early-onset PKD with ESRF in childhood. ${ }^{43}$

In the PKD1 gene, the location of the mutation appears to influence the disease severity with mutations in the $5^{\prime}$ portion of the gene $(0-7812 \mathrm{nt})$ associated with a lower

Table 1 Details of mutations identified

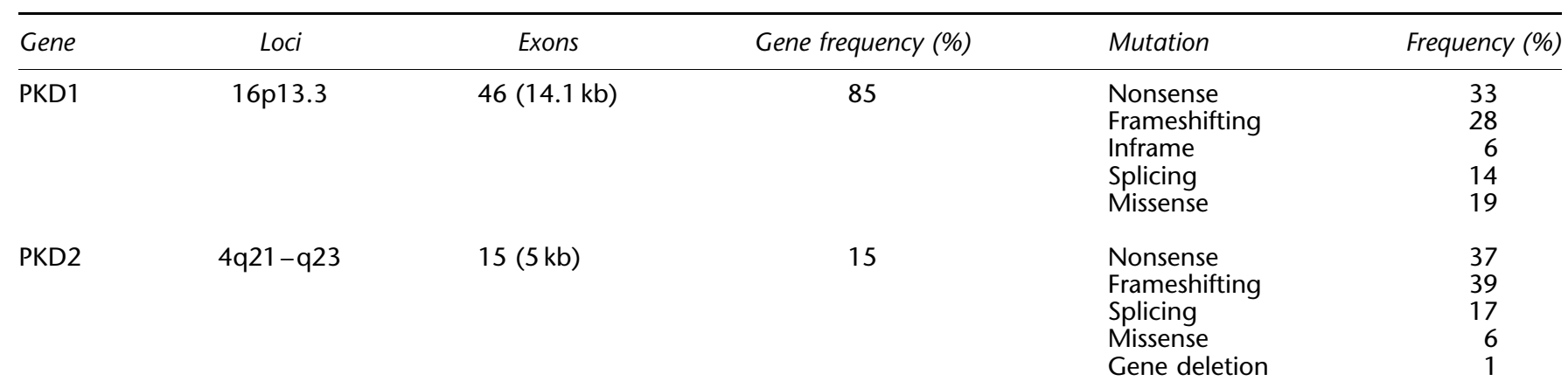

The figures given under the title frequency are taken from Rosetti $e t a l^{41}$ and Magistroni $e t a l^{42}$ and refer to the percentage of pedigrees with known mutations. 
mean age of ESRF than those $3^{\prime}$ of 7812 nt. ${ }^{44}$ In addition, it has been shown that a population of PKD1 patients presenting with a vascular phenotype have a median position of mutation located more $5^{\prime}$ than a control population. ${ }^{45}$ However, the widespread variation in clinical disease severity, especially the age of onset of renal failure, both within and between families, may be due to additional, as yet unidentified, genetic and environmental modifying factors. ${ }^{42,44}$ This clearly makes prediction of disease severity from knowledge of the mutation alone very difficult.

Germline and somatic mutations in PKD1 and PKD2 (including loss of heterozygosity) have been identified in cystic epithelia. ${ }^{46-48}$ This and support from gene targeting experiments in mice (see below) suggest a 'two-hit' model of cyst formation and provide an explanation for the focal nature of the disease.

\section{Protein function}

PKD1 encodes polycystin-1, a 4302-aa, 11 transmembrane domain protein with a large extracellular region and a short cytoplasmic C-terminal tail. ${ }^{30,49}$ PKD2 encodes polycystin-2, a 968-aa protein, with homology to members of the transient receptor potential (TRP) superfamily of $\mathrm{Ca}^{2+}$ permeable cation channels. ${ }^{31}$ Channel activation studies in a number of different cell systems have shown that polycystin- 2 can act as a $\mathrm{Ca}^{2+}$ permeable nonselective cation channel and is regulated by polycystin-1..$^{50-55}$ Further, it has been demonstrated that polycystin-1 and -2 form a complex via an interaction between their Ctermini and colocalise in the primary cilium of renal epithelial cells. ${ }^{56,57}$ They are both required for a mechanotransduction pathway, where flow stress on the primary cilia leads to an intracellular $\mathrm{Ca}^{2+}$ signalling response. ${ }^{58}$ Fibrocystin and inversin (associated with ARPKD and nephronophthisis type 2 respectively) also colocalise to the primary cilium, while OFD1 (associated with oro-facial digital syndrome type I) localises to the centrosome, at the base of the primary cilium. ${ }^{59-61}$ Abnormal cilial function is therefore a novel pathological mechanism in renal cyst formation.

Additionally, it has been shown that polycystin-1 is involved in cell cycle regulation via the JAK-STAT signalling pathway and in G-protein signalling via the JNK/AP1 pathway suggesting additional noncilial functions. ${ }^{62-64}$

\section{Animal models}

Targeted mutations in murine $P k d 1^{65-68}$ and $P k d 2^{69,70}$ have demonstrated that the polycystins have a major role in renal, cardiovascular, pancreatic and skeletal development. Polycystin-2 has a further role in left-right axis determination. ${ }^{70}$ The $P k d 1^{(d e l 17-21 \beta g e o)}$ mutant allele has been used to define the expression pattern of $P k d 1$ and demonstrates widespread expression in most tissues and cell types with highest levels in vascular smooth muscle cells and cartilage. ${ }^{67}$ In common with other cystic mouse mutations such as $c p k$, orpk and $i n v, P k d 1$ and $P k d 2$, mutant mice have a defect in cilial function. ${ }^{71}$ This provides further evidence for a common mechanism underlying renal cyst formation.

Renal cyst formation is mild in adult mice heterozygous for a $P k d 1$ or $P k d 2$ mutation but severe in homozygous embryos occurring from E15.5 onwards. In $P k d 2$ mice with an unstable mutant allele, that undergoes somatic inactivation by intragenic homologous recombination to produce a true null allele, and trans-heterozygous $P k d 1$ and $P k d 2$ mutant mice, cyst formation is severe. Thus identifying complete loss of function, somatic inactivation and genetic modifiers as important in cyst pathogenesis in ADPKD. ${ }^{72,73}$

\section{Clinical management}

There are no disease-specific therapies for any form of PKD. ${ }^{74}$ In addition, no evidence-based guidelines on the management of ADPKD have been reported perhaps due to the very slow rate of disease progression. In ADPKD, only blood pressure control has been shown to have a favourable impact on disease progression and cardiovascular complication rate. ${ }^{75,76}$ Monitoring of blood pressure should also be offered to at-risk relatives who have not been screened for ADPKD because of the high incidence of hypertension, even in children. ${ }^{11,77}$ Treatment should be started at pressures over $140 / 90 \mathrm{mmHg}$ with optimal levels of $130 / 85 \mathrm{mmHg}$ and even $125 / 75 \mathrm{mmHg} .{ }^{78}$ No trials have identified which antihypertensive agent is the agent of choice in ADPKD but angiotensin-converting enzyme inhibitors are the usual first-line agents and may be safer than diuretics. ${ }^{79}$

Patients with ADPKD are suitable for all forms of renal replacement therapy. Pre-dialysis or -transplant nephrectomy may be required for nephromegaly or recurrent sepsis. The increasing use of living related kidney donors is likely to lead to the increasing use of high-resolution imaging and molecular testing in the screening of potential donors. $^{80}$ Partial liver resection, or occasionally liver transplantation, may be performed if ADPKD is accompanied by symptomatic massive polycystic liver disease (Figure 2). Surgical intervention in ADPKD may also be indicated for the management of pain, haemorrhage and recurrent infection. Laparoscopy may have significant advantages over open surgery. ${ }^{81}$

In all families with ADPKD a history of intracranial aneurysm (ICA) must be sought. While routine screening for asymptomatic ICA in all ADPKD individuals is not warranted, in families with a proven case of ICA, the risk to other affected individuals is increased ( $\sim 16 \%)$ and screen- 

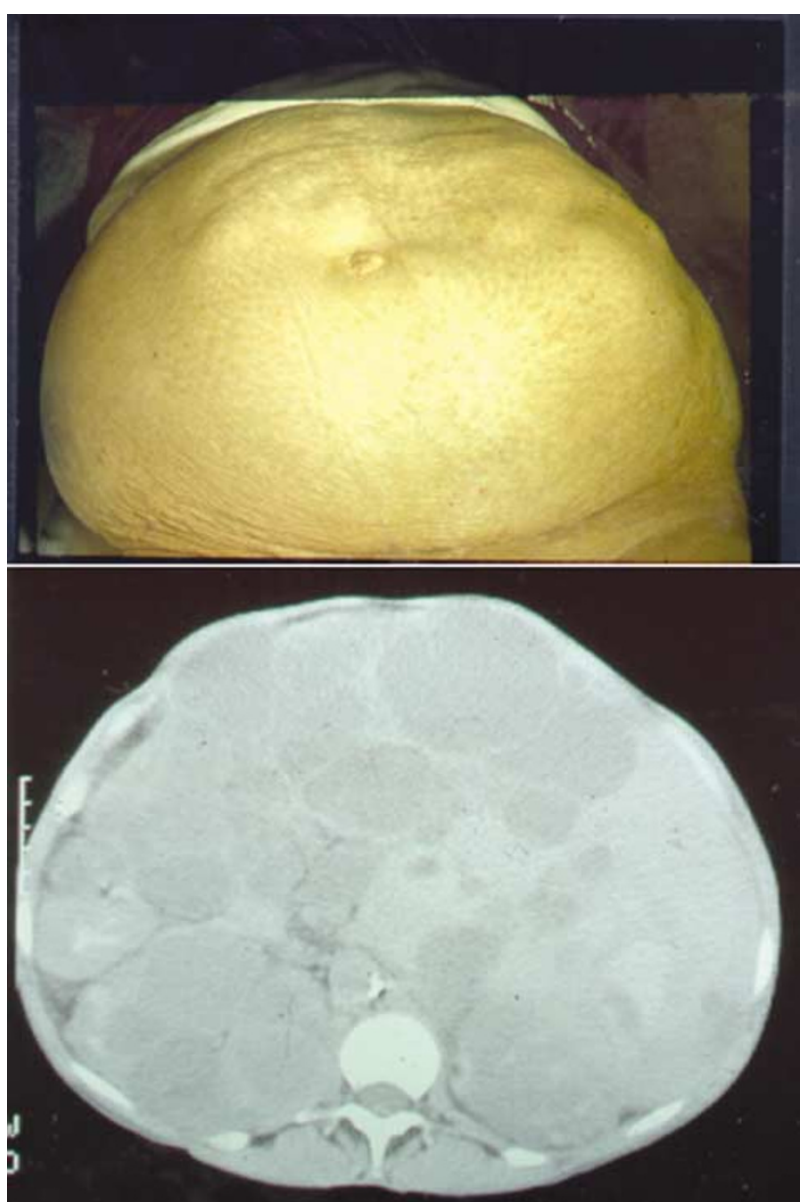

Figure 2 Abdominal distension due to polycystic liver disease in ADPKD. A CT scan demonstrates the presence of polycystic kidney disease and polycystic liver disease.

ing with magnetic resonance angiography should be considered in consultation with a neurosurgeon. ${ }^{6}$ Periodic screening every 3-5 years has been suggested for individuals with a family history and a reasonable life expectancy. Previous rupture of an ICA is also an indication for continued screening because of the high recurrence rate $(\sim 25 \%){ }^{82}$ For patients with positive screening for ICA, aneurysms greater than $10 \mathrm{~mm}$ should be considered for appropriate treatment. Periodic surveillance should be offered for smaller ICA. Given that there is considerable disagreement about the correct management of ICA, further recommendations in ADPKD will require prospective randomised trials.

All individuals with or at-risk of inheriting ADPKD should be offered genetic counselling to discuss genetic risk, screening, prenatal and predictive testing. ${ }^{83}$ Currently in the United Kingdom, molecular diagnosis and testing is available only by linkage analysis or where a clearly pathogenic mutation has been identified as part of a research project. With the low uptake of prenatal diagnosis and the wide availability of ultrasound, CT and MR imaging the clinical indications for molecular testing are restricted to only a small number of families.

Until recently, the progression of ADPKD was followed by the development of hypertension and elevation of serum creatinine. The latter only occurs in the late stages of the disease leaving a prolonged, usually asymptomatic, period in which progression was assumed but not measured. Data now suggest that measurement of renal volumes and renal blood flow may be a useful clinical measure of progression. ${ }^{84-86}$ The rate of change of renal volume with renal blood flow, coupled with genotype and other markers of disease severity, may allow the early identification of patients at high risk of developing renal failure in whom more aggressive treatment of blood pressure may be warranted.

Over the last three decades, mortality in ADPKD has been principally related to cardiac disease and sepsis. ${ }^{87}$ This represents the successful introduction of renal replacement programmes over this period and highlights the need for accurate assessment and treatment of cardiovascular risk factors in this group of patients.

Recent studies using different rodent models of renal cystic diseases have suggested that various pharmacological interventions may modify disease progression. A novel tyrosine kinase inhibitor EKI-785; pioglitazone, a thiazolidinedione compound and a vasopressin V2 receptor antagonist have all been shown to beneficially modify the course of murine cystic disease. ${ }^{88-90}$ This clearly demonstrates that a better understanding of the molecular and cellular defects underlying cystogenesis may lead to the design of novel, or the use of existing, therapeutic agents. It is therefore likely that trials in human ADPKD will be carried out in the near future, especially as methods for assessing disease progression in the short term are now available. $^{84,85}$

\section{Summary}

ADPKD is a common and severe clinical condition leading to renal failure and cardiovascular disease in the majority of affected individuals. Mutations in PKD1 and PKD2 that account for virtually all cases, result in abnormal function of the renal primary cilium. This newly identified disease mechanism appears to underlie several other types of renal cystic disease including those associated with more complex developmental defects such as Bardet-Biedl syndrome. $^{91}$ Although no disease-specific therapies are currently available, the discovery of a single common pathogenic mechanism in renal cystic diseases and the identification of agents that ameliorate murine polycystic kidney disease provide valuable and exciting impetus for the search for specific pharmacological agents for the management of ADPKD. 
Joint management of families with ADPKD by nephrologists and clinical geneticists will ensure the appropriate use of screening and molecular testing for at-risk individuals and may also allow the identification of individuals at high risk of developing complications such as renal failure. Clinical studies are still required to determine the utility of genotype data in the management of ADPKD; the best method for monitoring early disease progression and the most suitable antihypertensive agents. In a disease that has its main complications in later life, the slowing of progression to renal failure by only a decade could have a significant impact of morbidity and mortality.

\section{References}

1 Nicolau C, Torra R, Bianchi L et al: Abdominal sonographic study of autosomal dominant polycystic kidney disease. I Clin Ultrasound 2000; 28: 277-282.

2 Danaci M, Akpolat T, Bastemir M et al: The prevalence of seminal vesicle cysts in autosomal dominant polycystic kidney disease. Nephrol Dial Transplant 1998; 13: 2825-2828.

3 Gabow PA, Johnson AM, Kaehny WD, Manco-Johnson ML, Duley IT, Everson GT: Risk factors for the development of hepatic cysts in autosomal dominant polycystic kidney disease. Hepatology 1990; 11: 1033-1037.

4 Gabow PA, Johnson AM, Kaehny WD et al: Factors affecting the progression of renal disease in autosomal-dominant polycystic kidney disease. Kidney Int 1992; 41: 1311-1319.

5 Johnson AM, Gabow PA: Identification of patients with autosomal dominant polycystic kidney disease at highest risk for end-stage renal disease. J Am Soc Nephrol 1997; 8: 1560-1567.

6 Pirson Y, Chauveau D, Torres V: Management of cerebral aneurysms in autosomal dominant polycystic kidney disease. J Am Soc Nephrol 2002; 13: 269-276.

7 Chauveau D, Pirson Y, Verellen-Dumoulin C, Macnicol A, Gonzalo A, Grunfeld JP: Intracranial aneurysms in autosomal dominant polycystic kidney disease. Kidney Int 1994; 45: $1140-1146$.

8 Morris-Stiff G, Coles G, Moore R, Jurewicz A, Lord R: Abdominal wall hernia in autosomal dominant polycystic kidney disease. $\mathrm{Br} \mathrm{J}$ Surg 1997; 84: 615-617.

9 Lederman ED, McCoy G, Conti DJ, Lee EC: Diverticulitis and polycystic kidney disease. Am Surg 2000; 66: 200-203.

10 Sharp CK, Zeligman BE, Johnson AM, Duley I, Gabow PA: Evaluation of colonic diverticular disease in autosomal dominant polycystic kidney disease without end-stage renal disease. Am J Kidney Dis 1999; 34: 863-868.

11 Ivy DD, Shaffer EM, Johnson AM, Kimberling WJ, Dobin A, Gabow PA: Cardiovascular abnormalities in children with autosomal dominant polycystic kidney disease. J Am Soc Nephrol 1995; 5: 2032-2036.

12 Fick-Brosnahan GM, Tran ZV, Johnson AM, Strain JD, Gabow PA: Progression of autosomal-dominant polycystic kidney disease in children. Kidney Int 2001; 59: 1654-1662.

13 MacDermot KD, Saggar-Malik AK, Economides DL, Jeffery S: Prenatal diagnosis of autosomal dominant polycystic kidney disease (PKD1) presenting in utero and prognosis for very early onset disease. J Med Genet 1998; 35: 13-16.

14 Fick-Brosnahan G, Johnson AM, Strain JD, Gabow PA: Renal asymmetry in children with autosomal dominant polycystic kidney disease. Am J Kidney Dis 1999; 34: 639-645.

15 Ravine D, Gibson RN, Walker RG, Sheffield LJ, Kincaidsmith P, Danks DM: Evaluation of ultrasonographic diagnostic-criteria for autosomal-dominant polycystic kidney disease-1. Lancet 1994; 343: 824-827.
16 Gabow PA, Kimberling WJ, Strain JD, Manco-Johnson ML, Johnson AM: Utility of ultrasonography in the diagnosis of autosomal dominant polycystic kidney disease in children. $J \mathrm{Am}$ Soc Nephrol 1997; 8: 105-110.

17 Bear JC, Parfrey PS, Morgan JM, Martin CJ, Cramer BC: Autosomal dominant polycystic kidney-disease - new information for genetic-counseling. Am J Med Genet 1992; 43: 548-553.

18 Demetriou K, Tziakouri C, Anninou K et al: Autosomal dominant polycystic kidney disease-type 2 . Ultrasound, genetic and clinical correlations. Nephrol Dial Transplant 2000; 15: 205-211.

19 Parfrey PS, Bear JC, Morgan J et al: The diagnosis and prognosis of autosomal dominant polycystic kidney disease. $N$ Engl J Med 1990; 323: 1085-1090.

20 Fick GM, Johnson AM, Strain JD et al: Characteristics of very early onset autosomal dominant polycystic kidney disease. J Am Soc Nephrol 1993; 3: 1863-1870.

21 Zerres K, Rudnik-Schoneborn S, Deget F: Childhood onset autosomal dominant polycystic kidney disease in sibs: clinical picture and recurrence risk. German Working Group on Paediatric Nephrology (Arbeitsgemeinschaft fur Padiatrische Nephrologie. J Med Genet 1993; 30: 583-588.

22 Golin CO, Johnson AM, Fick G, Gabow PA: Insurance for autosomal dominant polycystic kidney disease patients prior to end-stage renal disease. Am J Kidney Dis 1996; 27: 220-223.

23 Levine E, Slusher SL, Grantham JJ, Wetzel LH: Natural history of acquired renal cystic disease in dialysis patients: a prospective longitudinal CT study. AJR 1991; 156: 501-506.

24 Bakir AA, Hasnain M, Young S, Dunea G: Dialysis-associated renal cystic disease resembling autosomal dominant polycystic kidney disease: a report of two cases. Am J Nephrol 1999; 19: 519-522.

25 Oppenheimer GD: Polycystic disease of the kidney. Ann Surg 1934; 100: 1136-1158.

26 Dalgaard OZ: Bilateral polycystic disease of the kidneys. Acta Med Scand 1957; 158: 1-251.

27 Yersin C, Bovet P, Wauters JP, Schorderet DF, Pescia G, Paccaud F: Frequency and impact of autosomal dominant polycystic kidney disease in the Seychelles (Indian Ocean). Nephrol Dial Transplant 1997; 12: 2069-2074.

28 Paterson AD, Pei Y: Is there a third gene for autosomal dominant polycystic kidney disease? Kidney Int 1998; 54: 1759-1761.

29 Consortium TEPKD: The polycystic kidney disease 1 gene encodes a $14 \mathrm{~kb}$ transcript and lies within a duplicated region on chromosome 16. Cell 1994; 77: 881-894.

30 Hughes J, Ward CJ, Peral B et al: The polycystic kidney disease 1 (PKD1) gene encodes a novel protein with multiple cell recognition domains. Nat Genet 1995; 10: 151-160.

31 Mochizuki T, Wu G, Hayashi T et al: PKD2, a gene for polycystic kidney disease that encodes an integral membrane protein. Science 1996; 272: 1339-1342.

32 Hughes J, Ward CJ, Aspinwall R, Butler R, Harris PC: Identification of a human homologue of the sea urchin receptor for egg jelly: a polycystic kidney disease-like protein. Hum Mol Genet 1999; 8: 543-549.

33 Yuasa T, Venugopal B, Weremowicz S, Morton CC, Guo L, Zhou J: The sequence, expression, and chromosomal localization of a novel polycystic kidney disease 1-like gene, PKD1L1, in human. Genomics 2002; 79: 376-386.

34 Li A, Tian X, Sung SW, Somlo S: Identification of two novel polycystic kidney disease-1-like genes in human and mouse genomes. Genomics 2003; 81: 596-608.

35 Wu G, Hayashi T, Park JH et al: Identification of PKD2L, a human PKD2-related gene: tissue-specific expression and mapping to chromosome 10q25. Genomics 1998; 54: 564-568.

36 Guo L, Schreiber TH, Weremowicz S, Morton CC, Lee C, Zhou J: Identification and characterization of a novel polycystin family member, polycystin-L2, in mouse and human: sequence, expression, alternative splicing, and chromosomal localization. Genomics 2000; 64: 241-251.

37 Bogdanova N, Markoff A, Gerke V, McCluskey M, Horst J, Dworniczak B: Homologues to the first gene for autosomal 
dominant polycystic kidney disease are pseudogenes. Genomics 2001; 74: 333-341.

38 Hateboer N, Dijk M, Bogdanova $\mathrm{N}$ et al: Comparison of phenotypes of polycystic kideny disease types 1 and 2 . Lancet 1999; 353: 103-107.

39 Rossetti S, Chauveau D, Walker D et al: A complete mutation screen of the ADPKD genes by DHPLC. Kidney Int 2002; 61: $1588-1599$.

40 Thomas R, McConnell R, Whittacker J, Kirkpatrick P, Bradley J, Sandford R: Identification of mutations in the repeated part of the autosomal dominant polycystic kidney disease type 1 gene, PKD1, by long-range PCR. Am J Hum Genet 1999; 65: 39-49.

41 Rossetti S, Strmecki L, Gamble V et al: Mutation analysis of the entire PKD1 gene: genetic and diagnostic implications. Am J Hum Genet 2001; 68: 46-63.

42 Magistroni $\mathrm{R}$, He N, Wang $\mathrm{K}$ et al: Genotype-renal function correlation in type 2 autosomal dominant polycystic kidney disease. J Am Soc Nephrol 2003; 14: 1164-1174.

43 Brookcarter PT, Peral B, Ward CJ et al: Deletion of the Tsc2 and Pkd1 genes associated with severe infantile polycystic kidney-disease - a contiguous gene syndrome. Nat Genet 1994; 8: $328-332$.

44 Rossetti S, Burton S, Strmecki L et al: The position of the polycystic kidney disease 1 (PKD1) gene mutation correlates with the severity of renal disease. J Am Soc Nephrol 2002; 13: $1230-1237$.

45 Rossetti S, Chauveau D, Kubly V et al: Association of mutation position in polycystic kidney disease 1 (PKD1) gene and development of a vascular phenotype. Lancet 2003; 361: 2196-2201.

46 Qian F, Watnick TJ, Onuchic LF, Germino GG: The molecularbasis of focal cyst formation in human autosomal- dominant polycystic kidney-disease type-I. Cell 1996; 87: 979-987.

47 Koptides M, Hadjimichael C, Koupepidou P, Pierides A, Constantinou Deltas C: Germinal and somatic mutations in the PKD2 gene of renal cysts in autosomal dominant polycystic kidney disease. Hum Mol Genet 1999; 8: 509-513.

48 Watnick T, He N, Wang K et al: Mutations of PKD1 in ADPKD2 cysts suggest a pathogenic effect of trans-heterozygous mutations. Nat Genet 2000; 25: 143-144.

49 Consortium TIPKD: Polycystic kidney disease: the complete structure of the PKD1 gene and its protein. Cell 1995; 81: $289-298$.

50 Hanaoka K, Qian F, Boletta A et al: Co-assembly of polycystin-1 and -2 produces unique cation-permeable currents. Nature 2000; 408: 990-994.

51 Gonzalez-Perret S, Kim K, Ibarra C et al: Polycystin-2, the protein mutated in autosomal dominant polycystic kidney disease (ADPKD), is a $\mathrm{Ca}^{2+}$-permeable nonselective cation channel. Proc Natl Acad Sci USA 2001; 98: 1182-1187.

52 Vassilev PM, Guo L, Chen XZ et al: Polycystin-2 is a novel cation channel implicated in defective intracellular $\mathrm{Ca}(2+)$ homeostasis in polycystic kidney disease. Biochem Biophys Res Commun 2001; 282: $341-350$

53 Koulen P, Cai Y, Geng L et al: Polycystin-2 is an intracellular calcium release channel. Nat Cell Biol 2002; 4: 191-197.

54 Vandorpe DH, Wilhelm S, Jiang L et al: Cation channel regulation by $\mathrm{COOH}$-terminal cytoplasmic tail of polycystin-1: mutational and functional analysis. Physiol Genomics 2002; 8: $87-98$.

$55 \mathrm{Xu}$ GM, Gonzalez-Perrett S, Essafi M et al: Polycystin-1 activates and stabilizes the polycystin-2 channel. J Biol Chem 2003; 278: 1457-1462.

56 Tsiokas L, Kim E, Arnould T, Sukhatme VP, Walz G: Homo- and heterodimeric interactions between the gene products of PKD1 and PKD2. Proc Natl Acad Sci USA 1997; 94: 6965-6970.

57 Yoder BK, Hou X, Guay-Woodford LM: The polycystic kidney disease proteins, polycystin-1, polycystin-2, polaris, and cystin, are co-localized in renal cilia. J Am Soc Nephrol 2002; 13: $2508-2516$
58 Nauli SM, Alenghat FJ, Luo Y et al: Polycystins 1 and 2 mediate mechanosensation in the primary cilium of kidney cells. Nat Genet 2003; 33: 129-137.

59 Otto EA, Schermer B, Obara T et al: Mutations in INVS encoding inversin cause nephronophthisis type 2, linking renal cystic disease to the function of primary cilia and left-right axis determination. Nat Genet 2003; 34: 413-420.

60 Ward CJ, Yuan D, Masyuk TV et al: Cellular and subcellular localization of the ARPKD protein; fibrocystin is expressed on primary cilia. Hum Mol Genet 2003; 12: 2703-2710.

61 Romio L, Wright V, Price K et al: OFD1, the gene mutated in oralfacial-digital syndrome type 1 , is expressed in the metanephros and in human embryonic renal mesenchymal cells. J Am Soc Nephrol 2003; 14: 680-689.

62 Bhunia AK, Piontek K, Boletta A et al: PKD1 induces p21(waf1) and regulation of the cell cycle via direct activation of the JAKSTAT signaling pathway in a process requiring PKD2. Cell 2002; 109: $157-168$.

63 Arnould T, Kim E, Tsiokas L et al: The polycystic kidney disease 1 gene product mediates protein kinase $\mathrm{C}$ alpha-dependent and cJun N-terminal kinase-dependent activation of the transcription factor AP-1. J Biol Chem 1998; 273: 6013-6018.

64 Parnell SC, Magenheimer BS, Maser RL, Zien CA, Frischauf AM, Calvet JP: Polycystin-1 activation of c-Jun N-terminal kinase and AP-1 is mediated by heterotrimeric G proteins. J Biol Chem 2002; 277: 19566-19572.

$65 \mathrm{Lu} \mathrm{W}$, Peissel B, Babakhanlou $\mathrm{H}$ et al: Perinatal lethality with kidney and pancreas defects in mice with a targetted Pkd1 mutation. Nat Genet 1997; 17: 179-181.

66 Kim K, Drummond I, Ibraghimov-Beskrovnaya O, Klinger K, Arnaout MA: Polycystin 1 is required for the structural integrity of blood vessels. Proc Natl Acad Sci USA 2000; 97: $1731-1736$

67 Boulter C, Mulroy S, Webb S, Fleming S, Brindle K, Sandford R: Cardiovascular, skeletal, and renal defects in mice with a targeted disruption of the Pkd1 gene. Proc Natl Acad Sci USA 2001; 98: 12174-12179.

$68 \mathrm{Lu} \mathrm{W}$, Shen X, Pavlova A et al: Comparison of Pkd1-targeted mutants reveals that loss of polycystin-1 causes cystogenesis and bone defects. Hum Mol Genet 2001; 10: 2385-2396.

$69 \mathrm{Wu}$ GQ Dagati V, Cai YQ et al: Somatic inactivation of Pkd2 results in polycystic kidney disease. Cell 1998; 93: 177-188.

70 Pennekamp P, Karcher C, Fischer A et al: The ion channel polycystin-2 is required for left-right axis determination in mice. Curr Biol 2002; 12: 938-943.

71 Nauli SM, Alenghat FJ, Luo Y et al: Polycystins 1 and 2 mediate mechanosensation in the primary cilium of kidney cells. Nat Genet 2003; 33: 129-137.

$72 \mathrm{Wu}$ G, D'Agati V, Cai Y et al: Somatic inactivation of Pkd2 results in polycystic kidney disease. Cell 1998; 93: 177-188.

73 Wu G, Tian X, Nishimura S et al: Trans-heterozygous Pkd1 and Pkd2 mutations modify expression of polycystic kidney disease. Hum Mol Genet 2002; 11: 1845-1854.

74 Davis ID, MacRae Dell K, Sweeney WE, Avner ED: Can progression of autosomal dominant or autosomal recessive polycystic kidney disease be prevented? Semin Nephrol 2001; 21: $430-440$.

75 Schrier RW, McFann KK, Johnson AM: Epidemiological study of kidney survival in autosomal dominant polycystic kidney disease. Kidney Int 2003; 63: 678-685.

76 Schrier R, McFann K, Johnson A et al: Cardiac and renal effects of standard versus rigorous blood pressure control in autosomaldominant polycystic kidney disease: results of a seven-year prospective randomized study. I Am Soc Nephrol 2002; 13: $1733-1739$

77 Seeman T, Sikut M, Konrad M, Vondrichova H, Janda J, Scharer K: Blood pressure and renal function in autosomal dominant polycystic kidney disease. Pediatr Nephrol 1997; 11: 592-596.

78 Ramsay L, Williams B, Johnston G et al: Guidelines for management of hypertension: report of the third working party 
of the British Hypertension Society. J Hum Hypertens 1999; 13: 569-592.

79 Ecder T, Edelstein CL, Fick-Brosnahan GM et al: Diuretics versus angiotensin-converting enzyme inhibitors in autosomal dominant polycystic kidney disease. Am J Nephrol 2001; 21: 98-103.

80 Zand MS, Strang J, Dumlao M, Rubens D, Erturk E, Bronsther O: Screening a living kidney donor for polycystic kidney disease using heavily T2-weighted MRI. Am J Kidney Dis 2001; 37: 612-619.

81 Dunn MD, Clayman RV: Laparoscopic management of renal cystic disease. World J Urol 2000; 18: 272-277.

82 Belz MM, Fick-Brosnahan GM, Hughes RL et al: Recurrence of intracranial aneurysms in autosomal-dominant polycystic kidney disease. Kidney Int 2003; 63: 1824-1830.

83 Sujansky E, Kreutzer SB, Johnson AM, Lezotte DC, Schrier RW, Gabow PA: Attitudes of at-risk and affected individuals regarding presymptomatic testing for autosomal dominant polycystic kidney disease. Am J Med Genet 1990; 35: 510-515.

84 King BF, Torres VE, Brummer ME et al: Magnetic resonance measurements of renal blood flow as a marker of disease severity in autosomal-dominant polycystic kidney disease. Kidney Int 2003; 64: 2214-2221.
85 Chapman AB, Guay-Woodford LM, Grantham JJ et al: Renal structure in early autosomal-dominant polycystic kidney disease (ADPKD): The Consortium for Radiologic Imaging Studies of Polycystic Kidney Disease (CRISP) cohort. Kidney Int 2003; 64: 1035-1045.

86 Fick-Brosnahan GM, Belz MM, McFann KK, Johnson AM, Schrier RW: Relationship between renal volume growth and renal function in autosomal dominant polycystic kidney disease: a longitudinal study. Am J Kidney Dis 2002; 39: 1127-1134.

87 Fick GM, Johnson AM, Hammond WS, Gabow PA: Causes of death in autosomal dominant polycystic kidney disease. J Am Soc Nephrol 1995; 5: 2048-2056.

88 Sweeney WE, Chen Y, Nakanishi K, Frost P, Avner ED: Treatment of polycystic kidney disease with a novel tyrosine kinase inhibitor. Kidney Int 2000; 57: 33-40.

89 Muto S, Aiba A, Saito Y et al: Pioglitazone improves the phenotype and molecular defects of a targeted Pkd1 mutant. Hum Mol Genet 2002; 11: 1731-1742.

90 Gattone VH, Wang X, Harris PC, Torres VE: Inhibition of renal cystic disease development and progression by a vasopressin $\mathrm{V} 2$ receptor antagonist. Nat Med 2003; 9: 1323-1326.

91 Ansley SJ, Badano JL, Blacque OE et al: Basal body dysfunction is a likely cause of pleiotropic Bardet-Biedl syndrome. Nature 2003; 425: 628-633. 